\title{
Research on Stress Analysis and Control of Surrounding Rock of Trapezoidal Roadways Based on Complex Variable Theory
}

\author{
Zhiqiang Wang, ${ }^{1,2,3,4}$ Chao Wu $\mathbb{D},{ }^{1}$ Jianqiao Luo, ${ }^{1}$ Wenyu Lv$^{2}$ Lei Shi, ${ }^{1}$ and Peng Wang $\mathbb{I D}^{1}$ \\ ${ }^{1}$ School of Energy and Mining Engineering, China University of Mining es Technology (Beijing), Beijing 100083, China \\ ${ }^{2}$ State Key Laboratory of Coal Resources in Western China, Xi'an University of Science and Technology, Xi'an 710054, China \\ ${ }^{3}$ Beijing Key Laboratory for Precise Mining of Intergrown Energy and Resources, \\ China University of Mining and Technology (Beijing), Beijing 100083, China \\ ${ }^{4}$ National Demonstration Center for Experimental Safe Coal Mining and Geological Guarantee Education, \\ China University of Mining and Technology (Beijing), Beijing 100083, China
}

Correspondence should be addressed to Chao Wu; 743857503@qq.com

Received 5 May 2021; Revised 2 June 2021; Accepted 26 July 2021; Published 4 August 2021

Academic Editor: Rozaimi Ghazali

Copyright (c) 2021 Zhiqiang Wang et al. This is an open access article distributed under the Creative Commons Attribution License, which permits unrestricted use, distribution, and reproduction in any medium, provided the original work is properly cited.

\begin{abstract}
Aiming at the problem of the serious deformation of the mining roadways in the trapezoidal section of the coal mine, the method of combining theoretical analysis and field application is used to study the surrounding rock control method of the trapezoidal roadways. The conformal mapping function of the trapezoidal roadways is calculated by the theory of complex change, and then from the analytical solution of the tangential stress distributed in the surrounding rock of trapezoidal roadways which is under the influence of the bidirectional unequal pressure, homogeneous, isotropic, and elastic rock mass is obtained. Research studies show that the roof-stress distribution of the trapezoidal roadways is uniform and the confining pressure is small, while the two sidewalls and the floor are opposite. The stress distribution of the two sidewalls and the floor varies greatly, and the stress concentration factor is large. The top corner of the trapezoidal roadways is basically not affected by stress concentration, but the stress concentration coefficient at the bottom corner is relatively large, and reinforcement measures are required in the roadway support. Based on the aforementioned research results, the multisupport scheme of "bolting with wire mesh and anchor cable + W-type steel belt + joist steel shed support + anchor cable grouting" was proposed to the surrounding rock of trapezoidal roadways with large stress caused by mining influence, thus solving the actual mining problem.
\end{abstract}

\section{Introduction}

With the continuous increase of coal mining depth, the difficulty of roadway support technology is rising. Due to high ground pressure and complex ground stress, the surrounding rock of some roadways has become broken and cannot bear the mining pressure well, resulting in the continuous increase of the deformation of the roadway. Conventional support methods can hardly guarantee the expected support effect, and the roadway must be repaired with reinforcement or structure optimization [1-3]. By apprehending the stress distribution of the surrounding rock of the roadway, it can effectively help us to choose the shape, size, and support measures of the roadway more reasonably.
Trapezoidal roadways are widely distributed among coal mines in China. Such roadways are usually under a high confining pressure caused by complex stresses, with the uneven stress distribution. At present, approximate solutions are mostly used for nonaxisymmetric elastoplastic problems. Many scholars have conducted a lot of research on this method and obtained analytical solutions of the stress field and the plastic zone around the chamber under the condition of bidirectional unequal pressure [4-10]. References [11, 12] obtained the elastic-plastic perturbation solutions of the circular roadways under the action of bidirectional unequal pressure by using the perturbation method. Reference [13] based on the unified strength theory derived the boundary equation of the plastic zone of the roadway surrounding rock 
with the nonuniform stress field. Ma's team [14-16] proposed the "butterfly shape" failure theory of circular roadways under the condition of bidirectional unequal pressure and gave the judgment criterion. At the same time, the concept of the plastic zone shape coefficient was put forward, and the calculation formula of the plastic zone morphological coefficient was derived, which can be used to distinguish the morphological characteristics of the plastic zone.

The analytical method of complex function is the most superior in the plane problem of the orifice. Its characteristic is applying conformal transformation and the mapping function to transform the area of the complex orifice's (e.g., the rectangular, trapezoidal, arch, and other noncircular curves that are often used in the roadway section) $Z$ plane into the unit circle on the $\zeta$ plane. Namely, the orifice boundary is transformed into the unit circle boundary, which is conducive to simplifying the boundary conditions, thereby deducing the elastic analytical formula for the stress of the surrounding rock of the orifice, which has become a solution to the common method of different section shape chamber mechanics problems. Reference [17] deduced the analytic solution of surrounding rock stress of rectangular roadways based on complex variation theory and analyzed the distribution regularities of tangential stress in the surrounding rock of roadways with different lateral pressure coefficients. Reference [18] also derived the analytical solution of the surrounding rock stress of a circular roadway based on the theory of complex variation and combined it with Mohr-Coulomb criterion to derive the formula of broken range of surrounding rock plastic zone.

In summary, there are kinds of researches on the nonaxisymmetric elastic-plastic problems of circular, rectangular, and arched roadways. In view of the engineering background where most coal mine roadway still uses trapezoidal roadways as mining roadway and serious deformation, this paper is based on the theory of complex variation theory to solve the stress field of surrounding rock of trapezoidal roadways under the condition of bidirectional unequal pressure, and the control technology of the surrounding rock of trapezoidal roadways is studied based on this theoretical basis.

\section{Engineering Overview and Deformation Characteristics of Roadway Surrounding Rock}

The Laogongyingzi Mine is located in Chifeng City, Inner Mongolia Autonomous Region, China. The roadways section of the coal mine working face is a trapezoid with a top length of $3 \mathrm{~m}$, a bottom length of $4.6 \mathrm{~m}$, and a vertical height of $3 \mathrm{~m}$. The buried depth is $400 \mathrm{~m}$, the average thickness of the mined coal seam is about $4.2 \mathrm{~m}$, and $0 \sim 0.5 \mathrm{~m}$ false roofs will fall along with mining. The direct roof is dominated by mudstone and fine sandstone, with an average thickness of about $20 \mathrm{~m}$, while the floor is dominated by fine sandstone. During the mining, the working face advances at a speed of $7 \mathrm{~m} / \mathrm{d}$, and the mining intensity is severe.
The original support scheme of the roadway adopts the combined support of "cable between shelf and shed + steel belt." The roof and the two sidewalls are, respectively, laid with 6 rows of I-beam with the length of $800 \mathrm{~mm}$, and the spacing is $500 \mathrm{~mm}$, and then the back plate is laid. After that, the two sidewalls are supported by anchor cables. The anchor cables are made of $\Phi 22 \mathrm{~mm} \times 4000 \mathrm{~mm}$ high-strength prestressed low-relaxation steel strands. Three anchor cables are laid in each row with a distance of $1000 \mathrm{~mm}$. The first anchor cable is $300 \mathrm{~mm}$ away from the roof. When supporting the second anchor cable and the third anchor cable, a $150 \mathrm{~mm} \times 150 \mathrm{~mm} \times 10 \mathrm{~mm}$ pallet is used to match the I-beam.

During the mining of the working face, the surrounding rock of the mining roadway is unstable and deforms greatly, and the floor needs to be cleaned and repaired many times, which seriously restricts the normal mining efficiency of the working face, as shown in Figure 1. Its instability deformation characteristics are mainly as follows:

(1) The large deformation of the coal pillar sidewall shows the characteristics of sustainability and large range. Severe bulging and collapse of the coal pillar sidewall of the roadway happened; along the direction of the roadway, there is a range of more than $15 \mathrm{~m}$, and the bulging amount is about $1000 \mathrm{~mm}$. The bulging causes the I-beam to undergo obvious bending and deformation. A large area of the coal pillar sidewall collapsed, resulting in a large-scale cavity between the I-beam and the coal pillar sidewall, and the depth of part of the coal pillar sidewall was about $1500 \mathrm{~mm}$, resulting in failure of the bolt and I-beam support. The coal mine lays wooden boards between the I-beam and the broken coal body to increase the force-bearing area in order to achieve the purpose of controlling the deformation of the roadside. However, the effect was not good, the wooden boards were broken, and the bulging and collapse continued.

(2) The degree of deformation of solid coal sidewall is lower than that of coal pillar sidewall. During roadway excavation, the amount of deformation is small. When it is affected by the mining of the working face, the roadway deforms seriously. The displacement of the bulge is $500 \sim 750 \mathrm{~mm}$. Part of the I-beam is bent and deformed, and the damage range along the axial direction of the roadway is about $3 \mathrm{~m}$.

(3) The roadway roof subsidence is small, the subsidence is about $200 \mathrm{~mm}$, and the bending deformation of the steel strip is obvious, especially when it is affected by the mining of the working face, and part of the roof leaks. The floor heave of the roadway is obvious, and the measured maximum floor heave volume reaches more than $1000 \mathrm{~mm}$, presenting a state of extrusion failure which is high in the middle and low at both ends, as well as even tensile failure and forming cracks. 


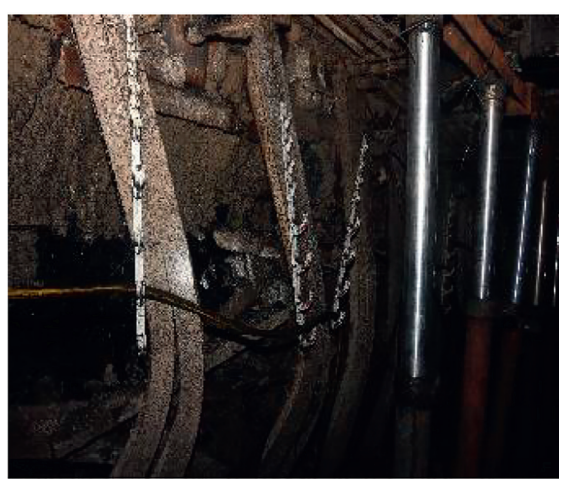

(a)

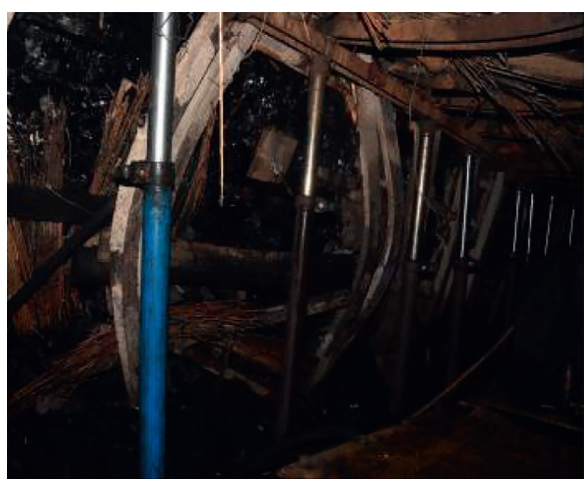

(b)

Figure 1: The mine pressure of the trapezoidal roadway. (a) The sidewalls of coal pillar heave for $1500 \mathrm{~mm}$. The I-beam bent. (b) The roof declined $500 \mathrm{~mm}$. The floor heaves seriously. The I-beam bent.

\section{Solution of Complex Variable Function of Stress in Surrounding Rock of Trapezoidal Roadways}

3.1. Steps to Solve Complex Variable Function of Roadways. From the polar coordinate stress transformation formula of elastic mechanics, the complex variable function expression of the stress component in the $\zeta$ plane polar coordinate is obtained according to the complex variable theory [19-21]:

$$
\left\{\begin{array}{l}
\sigma_{\theta}+\sigma_{\rho}=2[\Phi(\zeta)+\overline{\Phi(\zeta)}]=4 \operatorname{Re}[\Phi(\zeta)] \\
\sigma_{\theta}-\sigma_{\rho}+2 \mathrm{i} \tau_{\rho \theta}=\frac{2 \zeta^{2}}{\rho^{2} \overline{\omega^{\prime}(\zeta)}}\left[\overline{\omega(\zeta)} \Phi^{\prime}(\zeta)+\omega^{\prime}(\zeta) \Psi(\zeta)\right]
\end{array}\right.
$$

$$
\left\{\begin{array}{l}
\Phi(\zeta)=\varphi^{\prime}(\zeta)=\varphi^{\prime}[\omega(\zeta)]=\frac{\varphi^{\prime}(\zeta)}{\omega^{\prime}(\zeta)} \\
\Psi(\zeta)=\psi^{\prime}(\zeta)=\psi^{\prime}[\omega(\zeta)]=\frac{\psi^{\prime}(\zeta)}{\omega^{\prime}(\zeta)}
\end{array}\right.
$$

where $\sigma_{\theta}, \sigma_{\rho}$, and $\tau_{\rho \theta}$ are stress components of elastic body in the curvilinear coordinate system; $\varphi(\zeta), \psi(\zeta), \Phi(\zeta)$, and $\Psi(\zeta)$ are the complex potential analytic functions of complex variables $\zeta$; and $\omega(\zeta)$ is a conformal mapping function.

From elasticity theory and complex variable function theory, we obtained the following equation:

$$
\left\{\begin{array}{l}
\varphi(\zeta)=\frac{1+\mu}{8 \pi}\left(\overline{F_{x}}+i \overline{F_{y}}\right) \ln \zeta+B \omega(\zeta)+\varphi_{0}(\zeta) \\
\psi(\zeta)=\frac{3-\mu}{8 \pi}\left(\overline{F_{x}}-i \overline{F_{y}}\right) \ln \zeta+\left(B^{\prime}+i C^{\prime}\right) \omega(\zeta)+\psi_{0}(\zeta)
\end{array}\right.
$$

Considering $\sigma=\omega(\zeta)=e^{i \theta}, \sigma$ is the value of complex variable $\zeta$ at roadway boundary. Then, we get the boundary conditions expressed by $\varphi_{0}(\zeta)$ and $\psi_{0}(\zeta)$, which can be calculated by the following Cauchy integral equations:

$$
\begin{aligned}
& \varphi_{0}(\zeta)+\frac{1}{2 \pi i} \int_{\sigma} \frac{\omega(\sigma)}{\overline{\omega^{\prime}(\sigma)}} \frac{\overline{\varphi_{0}^{\prime}(\sigma)}}{\sigma-\zeta} \mathrm{d} \sigma=\frac{1}{2 \pi i} \int_{\sigma} \frac{f 0}{\sigma-\zeta} \mathrm{d} \sigma \\
& \psi_{0}(\zeta)+\frac{1}{2 \pi i} \int_{\sigma \overline{\omega^{\prime}(\sigma)}}^{\overline{\frac{\omega(\sigma)}{\sigma}}} \frac{\varphi_{0}^{\prime}(\sigma)}{\sigma-\zeta} \mathrm{d} \sigma=\frac{1}{2 \pi i} \int_{\sigma} \frac{\overline{f 0}}{\sigma-\zeta} \mathrm{d} \sigma,
\end{aligned}
$$

where $f_{0}$ is the known function for $\sigma$, and its expression is

$$
\begin{aligned}
f_{0}= & i \int\left(\overline{F_{x}}+i \overline{F_{y}}\right) \mathrm{d} s-\frac{\overline{F_{x}}-i \overline{F_{y}}}{2 \pi} \ln \sigma-\frac{1+\mu}{8 \pi}\left(\overline{F_{x}}-i \overline{F_{y}}\right) \\
& \times \frac{\omega(\sigma)}{\overline{\omega^{\prime}(\sigma)}} \sigma-2 B \omega(\sigma)-\left(B^{\prime}-i C^{\prime}\right) \overline{\omega(\sigma)},
\end{aligned}
$$

where $\mu$ is the elastic body shear modulus and $\overline{F_{x}}$ and $\overline{F_{y}}$ are the sum of surface force components $f_{x}$ and $f_{y}$ at orifice which are already known. $B, B^{\prime}$, and $C^{\prime}$ are related to the stress which is far from the orifice. The expressions are

$$
\begin{aligned}
& \left\{\begin{array}{l}
B=\frac{1}{4}\left(\sigma_{x}^{\infty}+\sigma_{y}^{\infty}\right), \\
B^{\prime}=\frac{1}{2}\left(\sigma_{y}^{\infty}-\sigma_{x}^{\infty}\right), \\
C^{\prime}=\tau_{x y}^{\infty},
\end{array}\right. \\
& \varphi_{0}(\zeta)=\sum_{k=1}^{n} \alpha_{k} \zeta^{k} \\
& \psi_{0}(\zeta)=\sum_{k=1}^{n} \beta_{k} \zeta^{k} .
\end{aligned}
$$

The following are the general steps of the complex function method to solve the orifice problems.

3.1.1. Conformal Transformation. Transform the area occupied by the elastic body on the $Z$ plane into the area on the $\zeta$ plane, and the general form of the trapezoidal roadway mapping function is [22] 


$$
\begin{aligned}
z & =\omega(\zeta)=R\left(\zeta+c_{0}+c_{1} \zeta^{-1}+c_{2} \zeta^{-2}+\cdots+c_{n} \zeta^{-n}\right) \\
& =R\left(\zeta+\sum_{k=0}^{\infty} c_{k} \zeta^{-k}\right)
\end{aligned}
$$

where $R$ is a real number, which is related to the orifice size, and $c_{k}$ is a complex number. The trapezoidal roadway discussed in this paper has an axis of symmetry, while $c_{k}$ in equation (10) must be a real number. The greater the $k$ series, the higher the accuracy, and generally $k=3$.

3.1.2. Solving for Stress Components. Mapping formula (10) for different shapes of orifices can be found from books on complex functions or established by the theory of complex functions. Substitute functions $\omega(\zeta)$ and equations (6)-(9) into equations (4) and (5), respectively, to get the equations of $\varphi_{0}(\zeta)$ and $\psi_{0}(\zeta)$ by applying Cauchy integral formula. Then calculate the equations of $\varphi(\zeta)$ and $\psi(\zeta)$, which can be obtained by equation (3). Substitute the equations of $\varphi(\zeta)$ and $\psi(\zeta)$ into equation (2) to find the equations of $\Phi(\zeta)$ and $\Psi(\zeta)$. Finally, substitute them into equation (1) to obtain the stress components $\sigma_{\theta}, \sigma_{\rho}$, and $\tau_{\rho \theta}$ in the curve coordinates.

\subsection{Analytical Solution of Tangential Stress of Surrounding Rock around Trapezoidal Roadways}

3.2.1. Conformal Mapping of Trapezoidal Roadways. The mechanical model of the trapezoidal roadway is established as shown in Figure 2. When the roadway has not been affected by mining stress, the stress distribution around the roadway is not affected by the leading support stress and lateral support stress, and it is subjected to bidirectional unequal compressive stresses; and the horizontal and vertical original rock stresses are evenly distributed. The length of the roadway in the $z$-axis direction is much larger than the length of the other two directions. The stress state is not considered. Therefore, the stress on any section of the roadway is simplified to an axisymmetric plane stress problem. The trapezoidal roadway on the $Z$ plane is mapped to the unit circle on the $\zeta$ plane through the conformal transformation method of the complex theory, as shown in Figure 3.

In the analysis of the left half of the symmetrical trapezoidal roadway, to facilitate calculation, divide the left half into 3 parts. Let the polar coordinates of any point around the trapezoidal roadway be $\left(r_{i}, \alpha_{i}\right)$. Let the polar coordinate of the corresponding mapping point on the unit circle be (1, $\beta_{i}$ ). Because the periphery of the roadway corresponds to the unit circle circumference on the plane, there are

$$
\begin{aligned}
r_{i} e^{i \alpha_{i}} & =R\left(e^{i \beta_{i}}+\sum_{k=0}^{\infty} c_{k} e^{-i k \beta_{i}}\right), \\
r_{i} & =R\left(e^{i\left(\beta_{i}-\alpha_{i}\right)}+\sum_{k=0}^{\infty} c_{k} e^{-i\left(k \beta_{i}+\alpha_{i}\right)}\right) .
\end{aligned}
$$
obtain

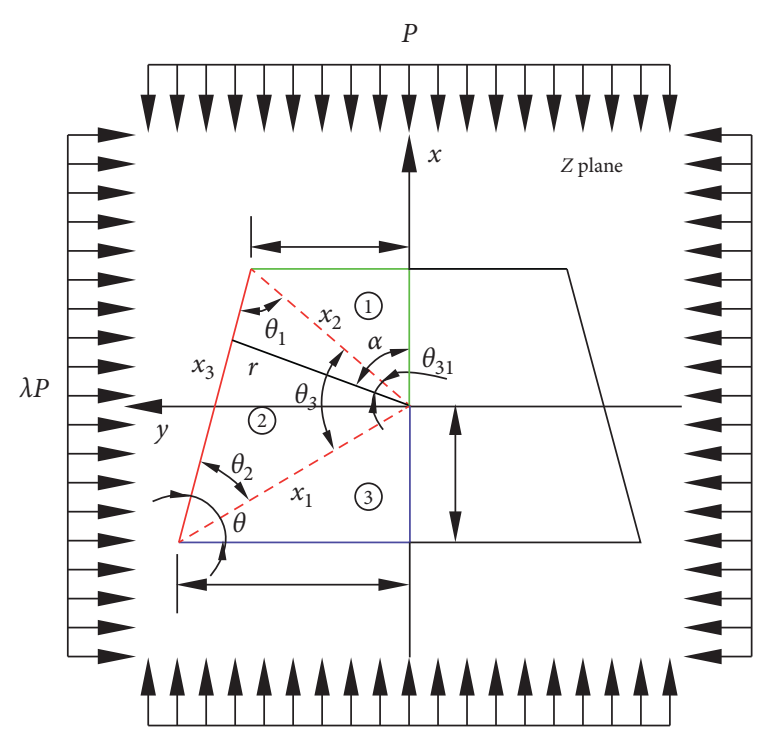

Figure 2: Trapezoidal roadways geometry on the $Z$ plane.

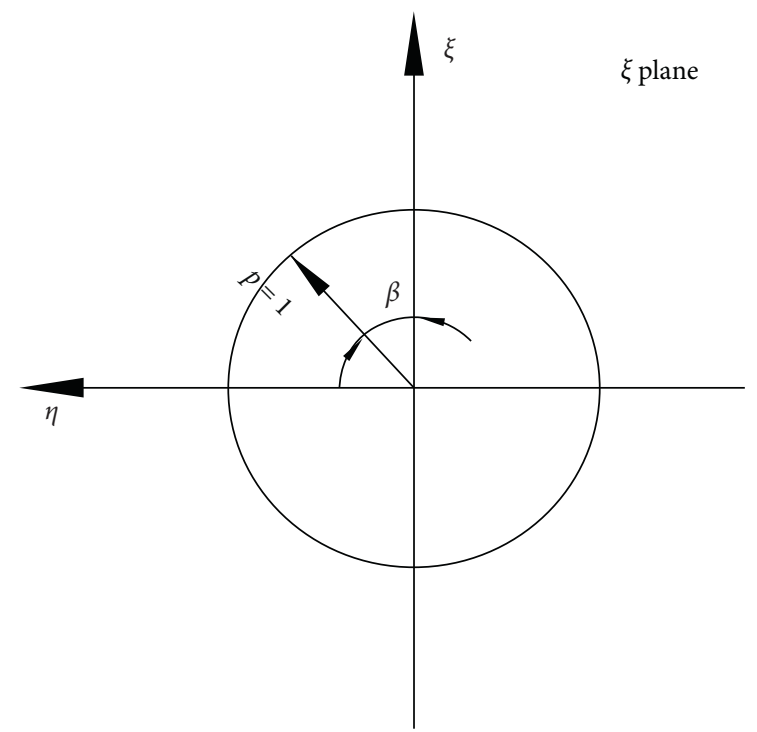

FIGURE 3: Unit circle of conformal mapping on the $\zeta$ plane.

$$
\begin{aligned}
& \sin \left(\beta_{i}-\alpha_{i}\right)+\sum_{k=0}^{\infty} c_{k} \sin \left(k \beta_{i}+\alpha_{i}\right)=0 \\
& r_{i}=R\left[\cos \left(\beta_{i}-\alpha_{i}\right)+\sum_{k=0}^{\infty} c_{k} \cos \left(k \beta_{i}+\alpha_{i}\right)\right] .
\end{aligned}
$$

According to the mathematical expression of the mapping function, now find $R$ and $c_{k}$ in the mapping function.

Select a rectangular coordinate system in the $Z$ plane, and set the $x$-axis as the symmetry axis of the roadway. On the periphery of the roadway on the left of the $x$-axis, take $m+1$ points in the counterclockwise direction. The rectangular coordinate value and the corresponding polar coordinate value of the $i$-th point are $\left(x_{i}, y_{i}\right)$ and $\left(r_{i}, \alpha_{i}\right)$, respectively. According to the geometric relationship of the 
trapezoidal roadway in Figure 2, the following equation can be found:

$$
\begin{cases}r_{1}=c \cos \alpha & \left(0 \leq \alpha \leq \arctan \frac{b}{c}\right), \\ r_{2}=\frac{x_{2}^{2}-x_{1}^{2}+x_{3}^{2}+2 \mathrm{~d} x_{3}}{2\left[x_{1} \cos \left(\theta_{3}-\theta_{31}\right)\right]-x_{2} \cos \theta_{31}} & \left(\arctan \frac{b}{c} \leq \alpha \leq \pi-\arctan \frac{a}{c}, 0 \leq \theta_{31} \leq \alpha-\arctan \frac{b}{c}\right), \\ r_{3}=c \cos (\pi-\alpha) & \left(\pi-\arctan \frac{a}{c} \leq \alpha \leq \pi\right) .\end{cases}
$$

Among them,

$$
\left\{\begin{array}{l}
x_{1}=\sqrt{a^{2}+c^{2}} \\
x_{2}=\sqrt{b^{2}+c^{2}} \\
x_{3}=\sqrt{x_{2}^{2}+x_{1}^{2}-2 x_{1} x_{2} \cos \left(\alpha-\arctan \frac{b}{c}\right)} \\
d=\frac{x_{2}^{2}-x_{1}^{2}-x_{3}^{2}+2 x_{1} x_{3} \cos \theta_{2}}{2 x_{1} \cos \theta_{2}+2 x_{2} \cos \theta_{1}-2 x_{3}} \\
\theta_{1}=\frac{\pi}{2}-\theta+\arctan \frac{b}{c} \\
\theta_{2}=\frac{\pi}{2}+\theta-\alpha, \\
\theta_{31}=\alpha-\arctan \frac{b}{c} \\
\theta=\arctan \frac{2 c}{a-b}
\end{array}\right.
$$

Let $i=1$ correspond to the polar coordinate point $\left(r_{1}, 0\right)$. Let the polar coordinate of the corresponding point on the circumference of the plane unit circle $\zeta$ be $(1,0)$. Then, $R_{1}$ can be obtained from equation (14) and $\alpha_{1}=\beta_{1}=0$, where

$$
R_{1}=\frac{r_{1}}{1+\sum_{k=0}^{\infty} c_{k}} .
$$

Let $i=3$ correspond to the polar coordinate point $\left(r_{2}\right.$, $\pi / 2)$. Let the polar coordinate of the corresponding point on the circumference of the plane unit circle $\zeta$ be $(1, \pi / 2)$. Then, $R_{2}$ can be obtained from formula (14) and $\alpha_{2}=\beta_{2}=\pi / 2$, where

$$
R_{2}=\frac{r_{2}}{1+\sum_{k=0}^{\infty} c_{k} \cos [(k+1) / 2 \pi]} .
$$

Let $i=5$ correspond to the polar coordinate point $\left(r_{3}, \pi\right)$. Let the polar coordinate of the corresponding point on the circumference of the plane unit circle $\zeta$ be $(1, \pi)$. Then, $R_{3}$ can be obtained from equation (14) and $\alpha_{3}=\beta_{3}=\pi$, where

$$
R_{3}=\frac{r_{3}}{1+\sum_{k=0}^{\infty} c_{k} \cos [(k+1) \pi]} .
$$

The three formulas above give the relationship between $R$ and $c_{k}$. From equation (14), when $k=0,1,2, \ldots, n, n$ takes a finite positive integer, and equation (14) cannot be accurately satisfied, but $c_{k}(k=0,1,2, \ldots, n)$ can be determined by optimization techniques. Meanwhile, the objective function can be taken as

$$
f=\sum_{i=1}^{m+1}\left\{r_{i}-R_{i}\left[\cos \left(\beta_{i}-\alpha_{i}\right)+\sum_{k=0}^{n} c_{k} \cos \left(k \beta_{i}+\alpha_{i}\right)\right]\right\}^{2} .
$$

In equation (18), $r_{i}$ and $\alpha_{i}$ are known values, $c_{k}$ is an unknown value, and $\beta_{i}$ is also an unknown value, but it can be connected with $c_{k}$ and $\alpha_{i}$ through equation (13).

When $m>n, c_{k}^{*}$ that minimizes $f$ can be obtained by equation (18). $c_{k}^{*}$ is the mapping function coefficient $c_{k}$ which is to be determined, and now $f_{\min }>0$.

According to the actual parameters of the trapezoidal roadways in one coal mine, let $a=2.3, b=1.5, c=1.5, n=3$, and $m=4$. In order to facilitate the calculation, take 5 special points of the trapezoidal roadway, and their polar coordinates are $(c, 0),\left(\sqrt{b^{2}+c^{2}}, \arctan b / c\right),(a+b / 2, \pi / 2)$, $\left(\sqrt{a^{2}+c^{2}}, \pi-\arctan a / c\right),(c, \pi)$. Substitute them into equations (8) and (9); $c_{k}$ is calculated by computer as $c_{0}=-0.1011, \quad c_{1}=-0.1101, \quad c_{2}=0.0859, \quad c_{3}=0.0014, \quad$ and $R=1.69$, and the mapping function of the trapezoidal section is determined as

$$
z=\omega(\zeta)=1.69 \times\left(\zeta-0.0896-\frac{0.1101}{\zeta}+\frac{0.0859}{\zeta^{2}}+\frac{0.0014}{\zeta^{3}}\right) .
$$

3.2.2. Analytical Formula for Tangential Stress of Surrounding Rock around Trapezoidal Roadway. Now perform calculation according to the steps of the complex 
variable function solution method; the following equation is derived by equation (6):

$$
\begin{aligned}
B & =\frac{1}{4}(P+\lambda P), \\
B^{\prime} & =\frac{1}{2}(\lambda P-P), \\
C^{\prime} & =0 .
\end{aligned}
$$

From equation (11), the following equation is derived:

$$
\left\{\begin{array}{l}
\omega(\sigma)=R\left(\sigma+c_{0}+c_{1} \frac{1}{\sigma}+c_{2} \frac{1}{\sigma^{2}}+c_{3} \frac{1}{\sigma^{3}}\right), \\
\overline{\omega(\sigma)}=R\left(\frac{1}{\sigma}+c_{0}+c_{1} \sigma+c_{2} \sigma^{2}+c_{3} \sigma^{3}\right), \\
\omega^{\prime}(\sigma)=R\left(1-c_{1} \frac{1}{\sigma^{2}}-c_{2} \frac{2}{\sigma^{3}}-c_{3} \frac{3}{\sigma^{4}}\right), \\
\overline{\omega^{\prime}(\sigma)}=R\left(1-c_{1} \sigma^{2}-2 c_{2} \sigma^{3}-3 c_{3} \sigma^{4}\right) .
\end{array}\right.
$$

Introducing equation (21) into equation (9) gives

$$
\begin{aligned}
f_{0}= & -2 B R\left(\sigma+c_{0}+c_{1} \frac{1}{\sigma}+c_{2} \frac{1}{\sigma^{2}}+c_{3} \frac{1}{\sigma^{3}}\right) \\
& -B^{\prime} R\left(\frac{1}{\sigma}+c_{0}+c_{1} \sigma+c_{2} \sigma^{2}+c_{3} \sigma^{3}\right) .
\end{aligned}
$$

Introducing equation (22) into equation (4) to solve with Harnack's theorem, the integral on the right is

$$
\frac{1}{2 \pi i} \int_{\sigma} \frac{f_{0}}{\sigma-\zeta} \mathrm{d} \sigma=-2 B R \zeta-B^{\prime} R c_{1} \zeta-B^{\prime} R c_{2} \zeta^{2}-B^{\prime} R c_{3} \zeta^{3} \text {. }
$$

Calculate by combining equations (4) and (13); then the solutions from $\alpha_{1}$ to $\alpha_{i}$ are found:

$$
\begin{aligned}
& \alpha_{1}=-B R, \alpha_{2}=-0.2746 B^{\prime} R, \alpha_{3}=-0.0096 B^{\prime} R, \\
& \alpha_{4}=\alpha_{5}=\cdots=\alpha_{n}=0 .
\end{aligned}
$$

Introduce them into formula (7) to get

$$
\varphi_{0}(\zeta)=-B R \zeta-0.2746 B^{\prime} R \zeta^{2}-0.0096 B^{\prime} R \zeta^{3} .
$$

Substituting equations (10) and (25) into equation (3) gives

$$
\varphi(\zeta)=B R\left(\zeta+c_{0}+c_{1} \zeta^{-1}+c_{2} \zeta^{-2}+\cdots+c_{n} \zeta^{-n}\right)-B R \zeta-0.2746 B^{\prime} R \zeta^{2}-0.0096 B^{\prime} R \zeta^{3}
$$

From equation (2),

$$
\begin{aligned}
\Phi(\zeta)= & \frac{\varphi^{\prime}(\zeta)}{\omega^{\prime}(\zeta)}=B \frac{-c_{1} \zeta^{2}-2 c_{2} \zeta-3 c_{3}}{\zeta^{4}-c_{1} \zeta^{2}-2 c_{2} \zeta-3 c_{3}} \\
& -B^{\prime} \frac{0.5492 \zeta^{5}+0.0288 \zeta^{7}}{\zeta^{4}-c_{1} \zeta^{2}-2 c_{2} \zeta-3 c_{3}} .
\end{aligned}
$$

Let $\rho$ of the unit circle which has already been mapped be 1 ; then $\zeta=\rho e^{i \theta}=e^{i \theta}=\cos \theta+i \sin \theta$. Substitute $\zeta$ into equation (27). After the calculation of the first half of equation (27), we have the following result:

$$
\begin{aligned}
B \frac{-c_{1} \zeta^{2}-2 c_{2} \zeta-3 c_{3}}{\zeta^{4}-c_{1} \zeta^{2}-2 c_{2} \zeta-3 c_{3}} & =-B \frac{c_{1} \cos 2 \theta+2 c_{2} \cos \theta+3 c_{3}+i\left(\sin 2 \theta+2 c_{2} \sin \theta\right)}{\cos 4 \theta-c_{1} \cos 2 \theta-2 c_{2} \cos \theta-3 c_{3}+i\left(\sin 4 \theta-c_{1} \sin 2 \theta-2 c_{2} \sin \theta\right)} \\
Z_{1}=\left(x_{1}, y_{1}\right) & =c_{1} \cos 2 \theta+2 c_{2} \cos \theta+3 c_{3}+i\left(\sin 2 \theta+2 c_{2} \sin 2 \theta\right) \\
Z_{2}=\left(x_{2}, y_{2}\right) & =\cos 4 \theta-c_{1} \cos 2 \theta-2 c_{2} \cos \theta-3 c_{3}+i\left(\sin 4 \theta-c_{1} \sin 2 \theta-2 c_{2} \sin \theta\right)
\end{aligned}
$$

Then,

$$
\operatorname{Re}\left(\frac{Z_{1}}{Z_{2}}\right)=\frac{x_{1} x_{2}+y_{1} y_{2}}{x_{2}^{2}+y_{2}^{2}}
$$

From equation (30),

$$
\left\{\begin{array}{l}
x_{1}=c_{1} \cos 2 \theta+2 c_{2} \cos \theta+3 c_{3}, \\
x_{2}=\cos 4 \theta-c_{1} \cos 2 \theta-2 c_{2} \cos \theta-3 c_{3}, \\
y_{1}=\sin 2 \theta+2 c_{2} \sin \theta \\
y_{2}=\sin 4 \theta-c_{1} \sin 2 \theta-2 c_{2} \sin \theta .
\end{array}\right.
$$

The calculation of the last half part of equation (27) gives 


$$
\begin{gathered}
-B^{\prime} \frac{0.5492 \zeta^{5}+0.0288 \zeta^{7}}{\zeta^{4}-c_{1} \zeta^{2}-2 c_{2} \zeta-3 c_{3}}=-B^{\prime} \frac{0.5492 \cos 5 \theta+0.0288 \cos 7 \theta+\mathrm{i}(0.5492 \sin 5 \theta+0.0288 \sin 7 \theta)}{\cos 4 \theta-c_{1} \cos 2 \theta-2 c_{2} \cos \theta-3 c_{3}+\mathrm{i}\left(\sin 4 \theta-c_{1} \sin 2 \theta-2 c_{2} \sin \theta\right)} \\
Z_{3}=\left(x_{3}, y_{3}\right)=0.5492 \cos 5 \theta+0.0288 \cos 7 \theta+\mathrm{i}(0.5492 \sin 5 \theta+0.0288 \sin 7 \theta)
\end{gathered}
$$

Then,

$$
\operatorname{Re}\left(\frac{Z_{3}}{Z_{2}}\right)=\frac{x_{2} x_{3}+y_{2} y_{3}}{x_{2}^{2}+y_{2}^{2}}
$$

From equation (34),

$$
\left\{\begin{array}{l}
x_{3}=0.5492 \cos 5 \theta+0.0288 \cos 7 \theta \\
y_{3}=0.5492 \sin 5 \theta+0.0288 \sin 7 \theta
\end{array}\right.
$$

Substitute equations (28), (30), (32), and (34) into formula (1). Because the value of $\sigma_{\rho}$ around the roadway is 0 , we have $\sigma_{\theta}=4 \operatorname{Re} \Phi(\zeta)$. The analytical equation for the tangential stress around the trapezoidal roadways is calculated as

$$
\sigma_{\theta}=(P+\lambda P)\left(\frac{x_{1} x_{2}+y_{1} y_{2}}{x_{2}^{2}+y_{2}^{2}}\right)+2(P-\lambda P)\left(\frac{x_{2} x_{3}+y_{2} y_{3}}{x_{2}^{2}+y_{2}^{2}}\right)
$$

\section{Engineering Application Examples}

The actual geological conditions and roadway parameters of the coal mine are as follows: the long side of the trapezoidal roadway is $4.6 \mathrm{~m}$, the short side is $3 \mathrm{~m}$, the height is $3 \mathrm{~m}, P$ is $10 \mathrm{MPa}$, and the lateral pressure coefficient is 0.8 .

Substitute the parameters above into equations (36), (34), and (32) to obtain the tangential stress values of surrounding rocks around the trapezoidal roadway, as in Table 1. According to Table 1, draw the tangential stress fitting curve of surrounding rocks around the trapezoidal roadways as shown in Figure 4; and the tangential stress distribution diagram of surrounding rock around the trapezoidal roadways is shown in Figure 5.

As illustrated in Figures 4 and 5, the tangential stress distribution of surrounding rocks around trapezoidal roadways is symmetrical, and the tangential stress rangeability from the roof $\left(0^{\circ}\right.$ angle) to the top angle $\left(45^{\circ}\right.$ angle, $315^{\circ}$ angle) is relatively small, while the two sidewalls $\left(60^{\circ}\right.$ angle, $300^{\circ}$ angle) transit to the bottom angle $\left(120^{\circ}\right.$ angle, $240^{\circ}$ angle $)$ and then to the floor $\left(180^{\circ}\right.$ angle $)$, the tangential stress varies greatly, and the maximum difference of stress is 12.3 $\mathrm{MPa}$.

After specific analysis, as shown in Figure 4, the tangential stress concentration degree of surrounding rock around trapezoidal roadway bottom angle $\left(110^{\circ}\right.$ angle) $>$ two sidewalls $\left(90^{\circ}\right.$ angle $)>\operatorname{roof}\left(0^{\circ}\right.$ angle $)>\operatorname{roof}\left(45^{\circ}\right.$ angle) $>$ floor $\left(180^{\circ}\right.$ angle), where the maximum stress concentration factor of the bottom angle is 2 , the second is
1.48 in the middle of the two sidewalls, and the minimum of the floor is 0.74 . According to the observation from the working face of a certain mine, the roadway roof deformation is not obvious. The main deformation positions are on the two sidewalls and the floor. The maximum deformation reaches $1500 \mathrm{~mm}$ and $1000 \mathrm{~mm}$, respectively, and the deformation patterns of the two sidewalls are similar to the tangential stress distribution state in Figure 5. The deformation of the upper part on the sidewall is small and the deformation of the lower sidewall is large, which has seriously affected the normal mining demand of the working face. Analyzing the reasons, it is believed that the tangential stress variation range of the surrounding rock around the roof is relatively gentle, so that the overall roof has a strong bearing capacity, and the stress concentration coefficient is not large, which is the reason for the fact that the deformation of the roof is not obvious; while the tangential stress of the surrounding rock from top to bottom of the two sidewalls has a big rangeability, and the surrounding rock's self-stabilization ability is feeble. Under the influence of high-strength mining, large deformation occurs at the lower sidewall of the coal and rock mass where the stress concentration is greater. Similarly, the tangential stress from the bottom corner to the middle of the floor has a big rangeability, and the stress concentration coefficient in the middle of the floor is less than 1 . The self-stable loadbearing capacity of the floor is weaker, and the large deformation of the two sidewalls reduces the load-bearing capacity, resulting in the transfer of high ground stress to the floor, which causes the floor to produce an extrusion type floor heave and tensile fracture.

Based on the above complex variable theory calculation and field engineering survey, it can be seen that, for surrounding rock of trapezoidal roadways, the large deformation of surrounding rock is mainly on the two sidewalls and floor, where the tangential stress has a big rangeability. Therefore, the two sidewalls and floor are the key parts to support the trapezoidal roadway.

\section{Surrounding Rock Control Technology of Trapezoidal Roadway}

5.1. Support Plan and Key Parameters. Based on the abovementioned trapezoidal roadway surrounding rock tangential stress distribution characteristics and field engineering roadway surrounding rock deformation characteristics, propose a support plan: bolting with wire mesh and anchor cable $+\mathrm{W}$-type steel belt + joist steel shed support + anchor cable grouting. The construction steps are as follows. 
TABLE 1: Tangential stress value at each point around trapezoidal roadways (unit: MPa).

\begin{tabular}{|c|c|c|c|c|c|c|c|c|c|c|c|c|c|}
\hline & $0^{\circ}$ & $15^{\circ}$ & $30^{\circ}$ & $45^{\circ}$ & $60^{\circ}$ & $75^{\circ}$ & $90^{\circ}$ & $105^{\circ}$ & $120^{\circ}$ & $135^{\circ}$ & $150^{\circ}$ & $165^{\circ}$ & $180^{\circ}$ \\
\hline Tangential stress & 13.792 & 12.678 & 10.707 & 9.496 & 9.539 & 11.132 & 14.785 & 19.6 & 19.706 & 14.45 & 10.139 & 7.994 & 7.372 \\
\hline
\end{tabular}

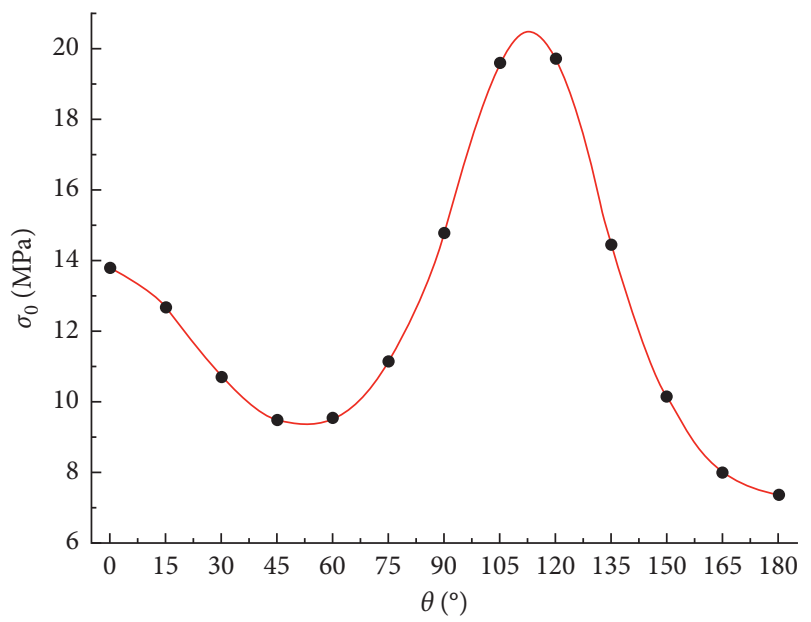

FIGURE 4: Fitting curve of tangential stress value of surrounding rock around trapezoidal roadways.

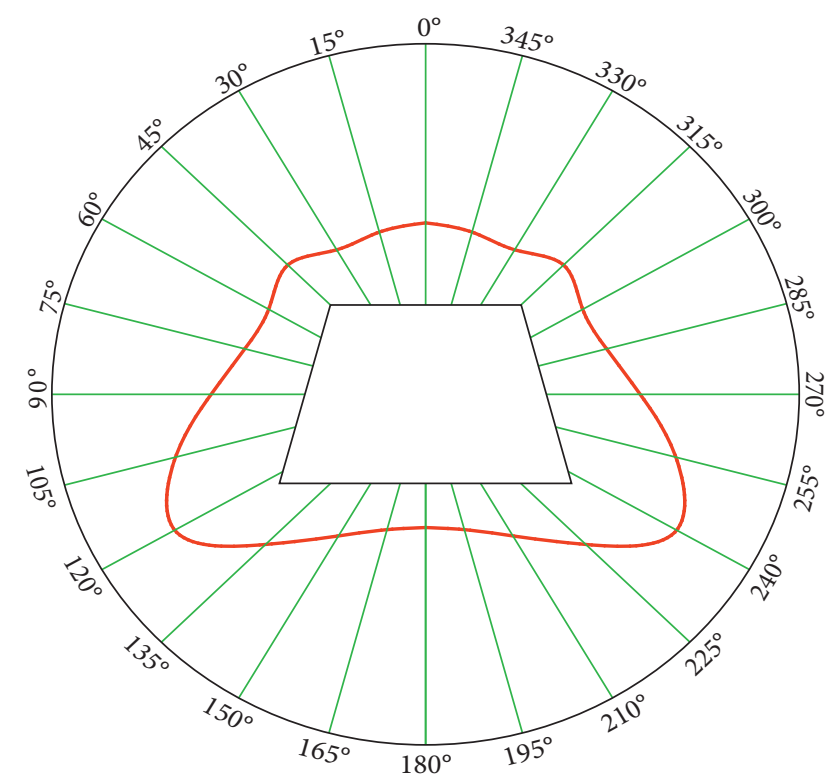

Figure 5: Schematic diagram of tangential stress distribution in surrounding rocks of trapezoidal roadways.

First of all, after the excavation of the roadway, the bolting with wire mesh and anchor cable $+\mathrm{W}$-type steel belt should be timely supported. Then observe the change rate of stress and displacement of the roadway surrounding rock, and carry out the secondary support of the joist steel shed support with high strength and large stiffness when the deformation rate of roadway is slow. According to the onsite monitoring results of the coal mine, the support position of the joist steel shed generally lags behind the tunneling face by $20 \sim 40 \mathrm{~m}$. For the geological conditions of the trapezoidal roadway, the coal seam and the roof and the floor rock strength are low, and the two sidewalls of the roadway will produce a large amount of deformation, which cannot be stable by using the joist steel bracket only. At the same time, the stress of the surrounding rock at the roof is imposed on the top beam, and the top beam is transmitted to the floor through the shed's legs. If the floor is not supported, the floor heave phenomenon will inevitably occur. Therefore, three times of anchor cable grouting support should be carried out at the end. The support time is selected after the secondary support when the two sidewalls of the roadway are further deformed and compressed backplane, that is, shortly after being affected by the mining stress but before the influence of the advanced support stress of the working face. The secondary cracks in the roadway are relatively developed at this time, the grouting effect is good, and the damage and destruction of the joist steel bracket and the floor heave caused by the large deformation of the two sidewalls under the influence of mining are avoided.

The initial and timely support layout is shown in Figure 6.

Combined with the aforementioned theoretical analysis results of the tangential stress distribution of the trapezoidal roadways, it is believed that the stress distribution of the roof is stable, and the stress concentration is only slightly higher in the middle of the roof. Therefore, one anchor cable is installed in each row in the middle of the roof. The tangential stress distributions of the two sidewalls are extremely uneven, and the stress concentration of the lower sidewall is large, so the lower sidewall is the most deformed part. When the timely support is operating, do not install the anchor cable, allow the sidewalls to deform properly so that it will release part of the deformation energy first, which could increase the development degree of secondary cracks, and create conditions for the third-time anchor cable grouting support. Only one anchor cable is installed in each row of the upper sidewall to increase the strength of the upper sidewall support. Rock bolts should be laid first, and anchor cables should be laid uniformly when carrying out joist steel shed support. Support parameters are mainly selected for the existing support equipment in the mine.

The secondary support arrangement is shown in Figure 7.

Six rows of joist steel are laid on the roof as well as the two sidewalls at a distance of $500 \mathrm{~mm}$, and then the backplate is laid for anchor cable support. The anchor cable adopts $\Phi 22 \mathrm{~mm} \times 4000 \mathrm{~mm}$ high-strength prestressed and low-relaxation steel strands. The installation position is shown in Figure 6; the roof and upper anchor cables use $300 \mathrm{~mm} \times 300 \mathrm{~mm} \times 14 \mathrm{~mm}$ pallets and $800 \mathrm{~mm}$ I-beam to provide a reaction force for the support, which is equivalent to adding some nodes at the support and effectively enhancing the bearing capacity of the metal support. 


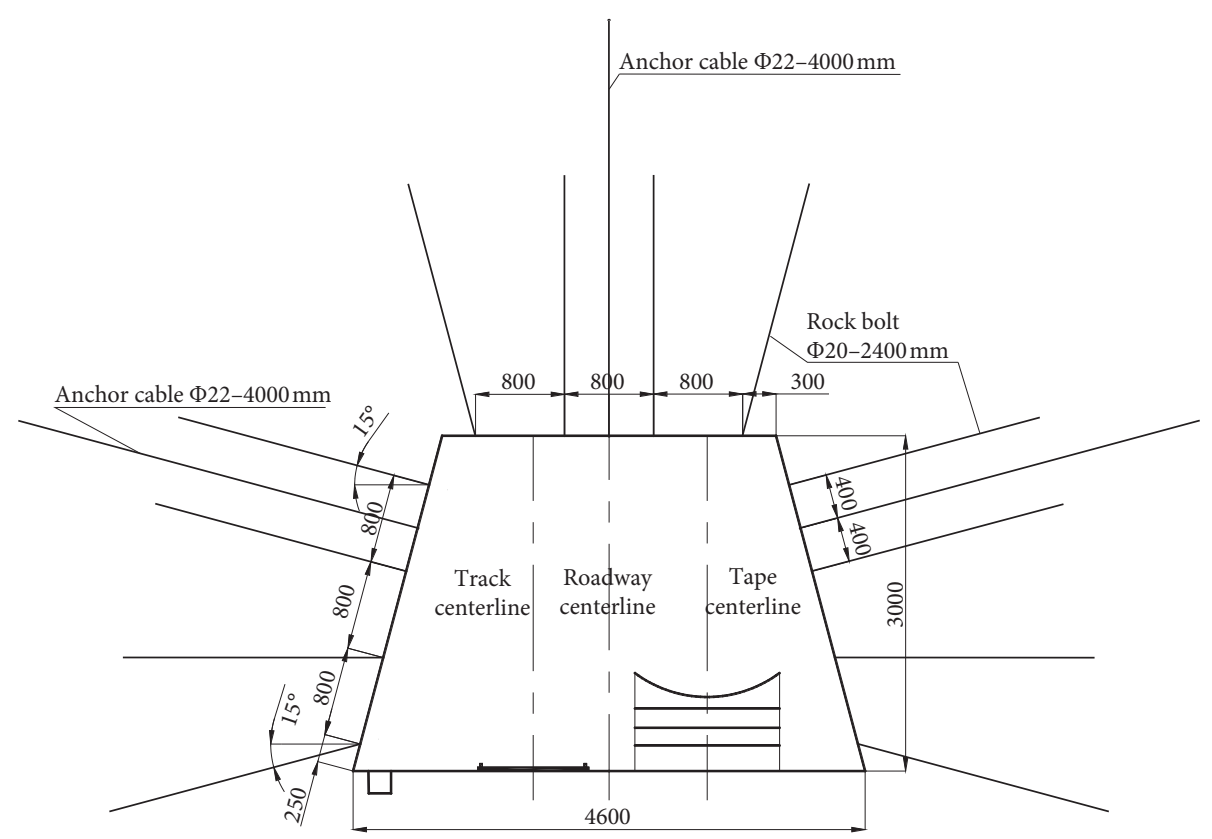

(a)

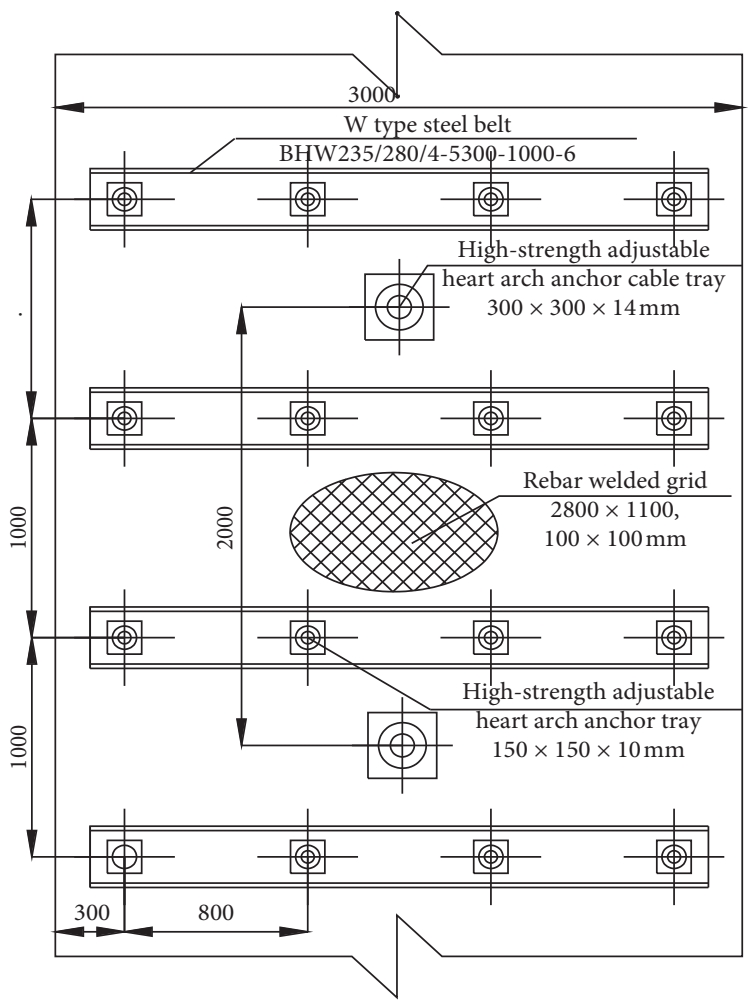

(b)

Figure 6: Continued. 


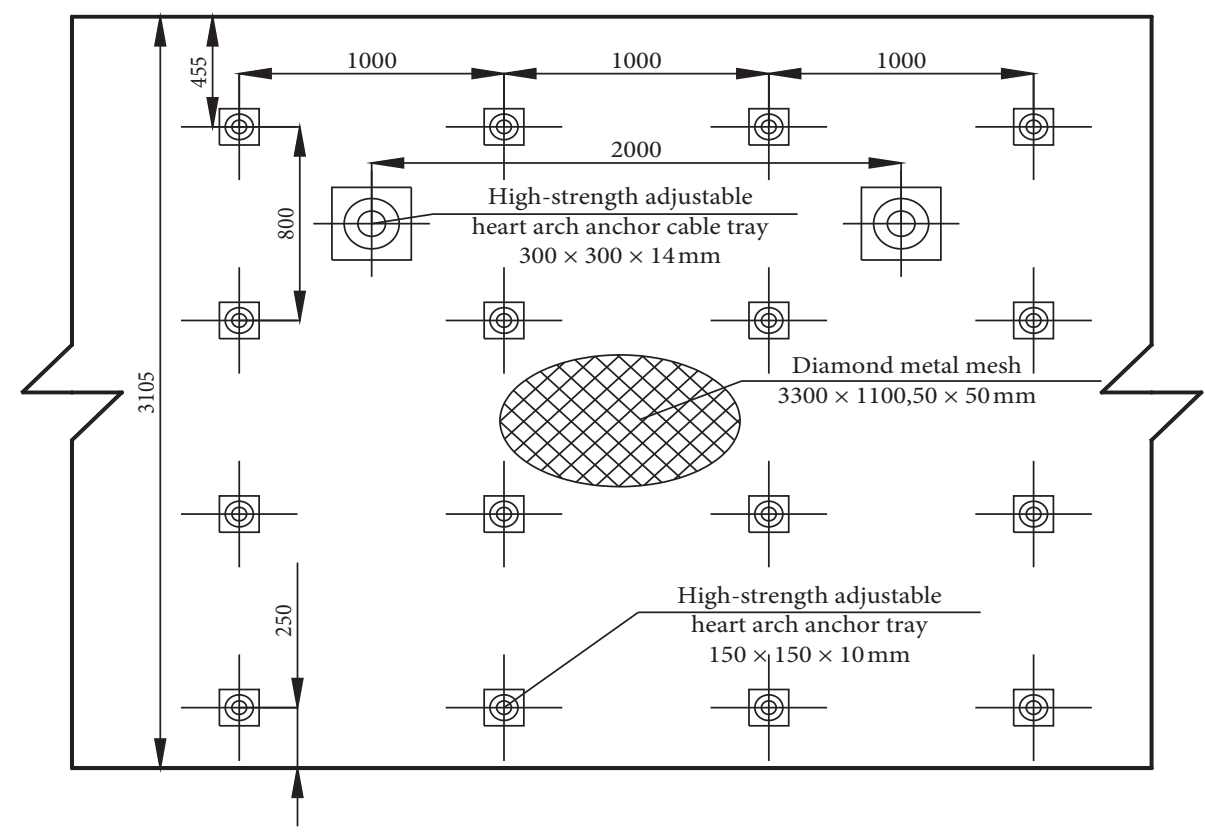

(c)

FIGURE 6: Initial and timely support layout. (a) Roadway section support diagram. (b) Roof support plan. (c) Sidewalls support plan.

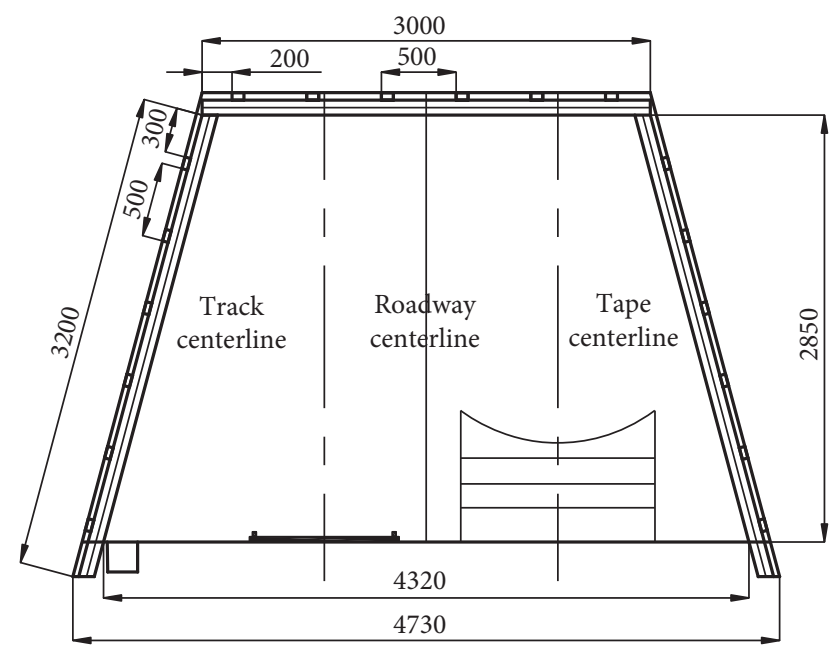

Figure 7: Joist steel shed support diagram.

The third-time anchor cable grouting support arrangement is shown in Figure 8.

The deep hole grouting adopts a $5 \mathrm{~m}$ grouting anchor cable. First of all, the grouting anchor cable is driven into the surrounding rock, and then deep grouting is carried out. Generally, the grouting pressure is controlled at $3 \sim 4 \mathrm{MPa}$, and the grouting diffusion radius is $1.5 \sim 2.0 \mathrm{~m}$. Drilling at an angle of $15^{\circ}$ can make the anchor cable hit the rock layer of the floor, and the spreading range of the grout can spread to the lower side and floor where the stress concentration is large. By improving the mechanical parameters of the surrounding rock in the grouting reinforcement area and enhancing the integrity of the loose coal body, the surrounding rock of the two sidewalls and the floor is transformed from the load-applying body of the joist steel shed support into the joint bearing body.

In conclusion, the joint support plan of the surrounding rock of trapezoidal roadway is obtained finally as shown in Figure 9.

5.2. Effect of Application. A rail roadway in this mine is chosen for the experiment. The rail roadway was influenced twice by the mining activities: one occurred in 105(7) working face and the other occurred in 105(8) working face. The above supporting scheme was applied in the actual construction of test roadway. Using cross distribution method to observe the deformation of roadway surrounding rock and the observation station layout is shown in Figure 10.

The monitoring data of No. I observation station are shown in Figures 11 and 12. The monitoring data indicate that after mining influence of 105(7) working face and the goaf is gradually stable, the maximum displacement of two sidewalls of roadway reaches $210 \mathrm{~mm}$, the maximum displacement of the roof and floor reaches $140 \mathrm{~mm}$, and the floor heave is up to $120 \mathrm{~mm}$. During the advancing process of 105(8) working face, two sidewalls of roadway amplification are $50 \mathrm{~mm}$, and floor heave amplification is $20 \mathrm{~mm}$, which all mean the deformation of roadway is small. The support effect is shown in Figure 13. The surface of the roadway is flat, and the pillars of the roadway's advanced support section do not bend or break under the condition of wood support. The support scheme is proved to meet the requirements of high-intensity mining activities and will ensure the safe and efficient mining in the whole working face. 


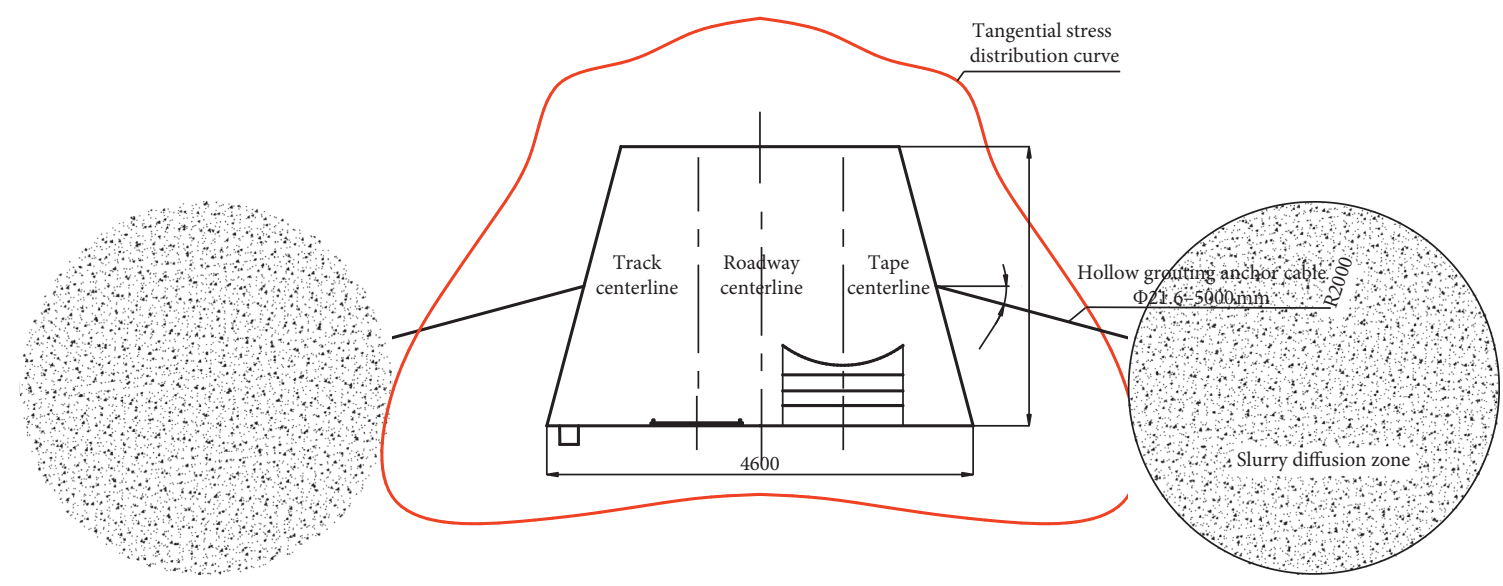

FIGURE 8: Third-time anchor cable grouting support arrangement plan.

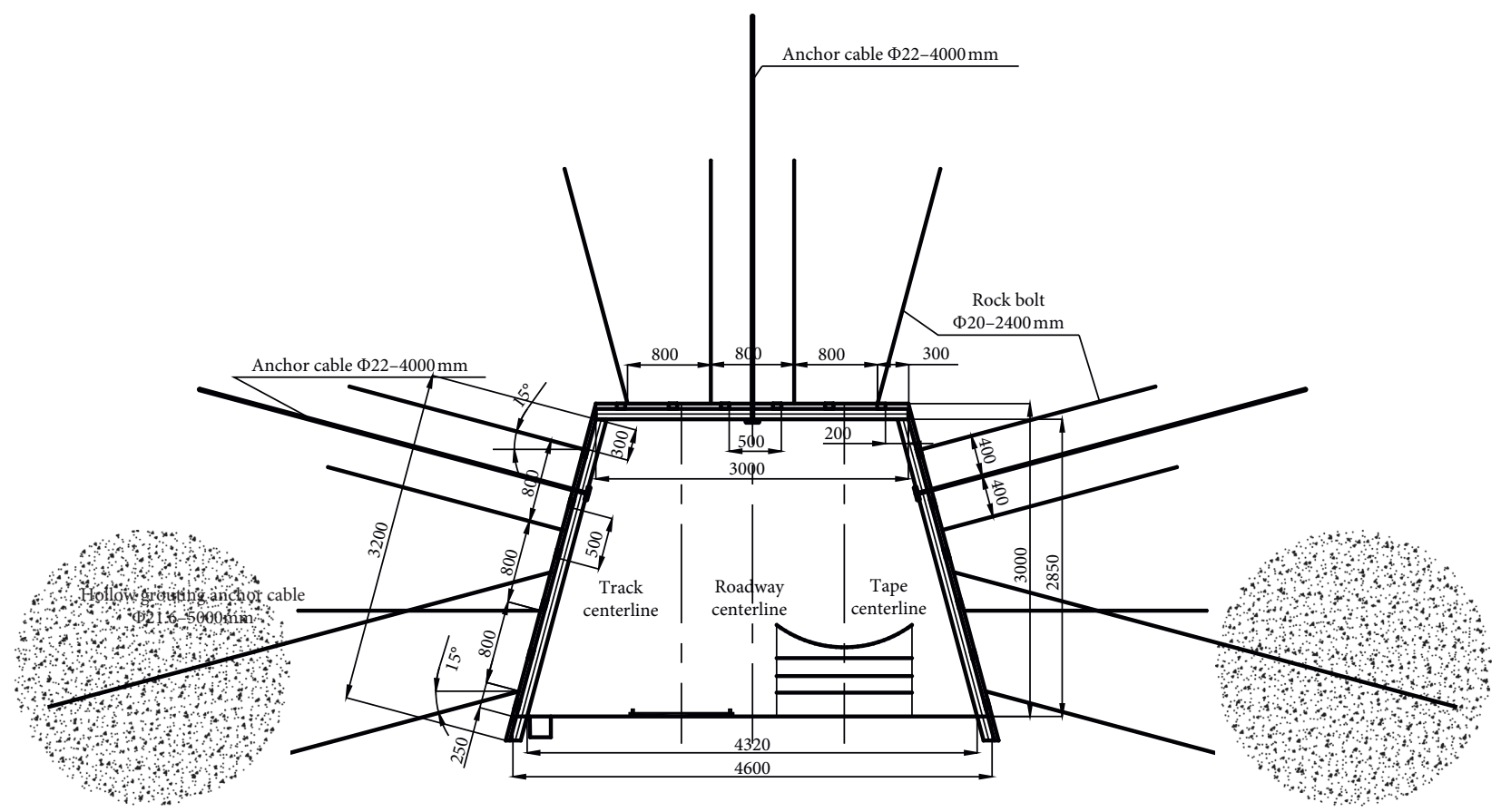

(a)

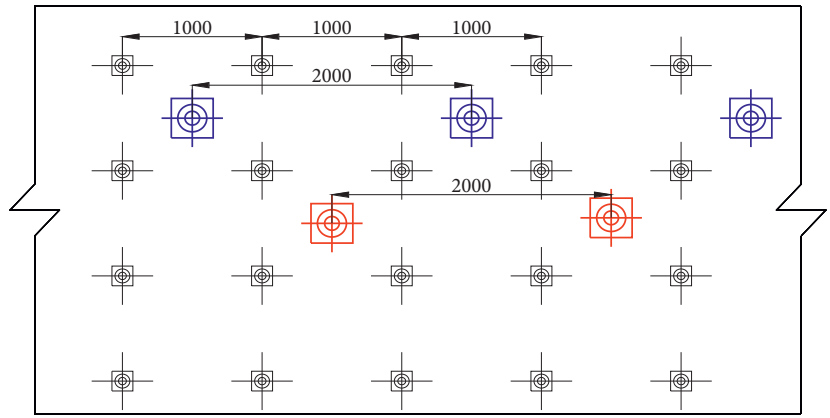

(9) Grouting anchor cable

[0 Ordinary anchor cable

(9) Rock bolt

(b)

FIGURE 9: Combined support scheme for trapezoidal roadway. (a) Sectional drawing of joint support scheme. (b) Two-sidewall plan of joint support plan. 


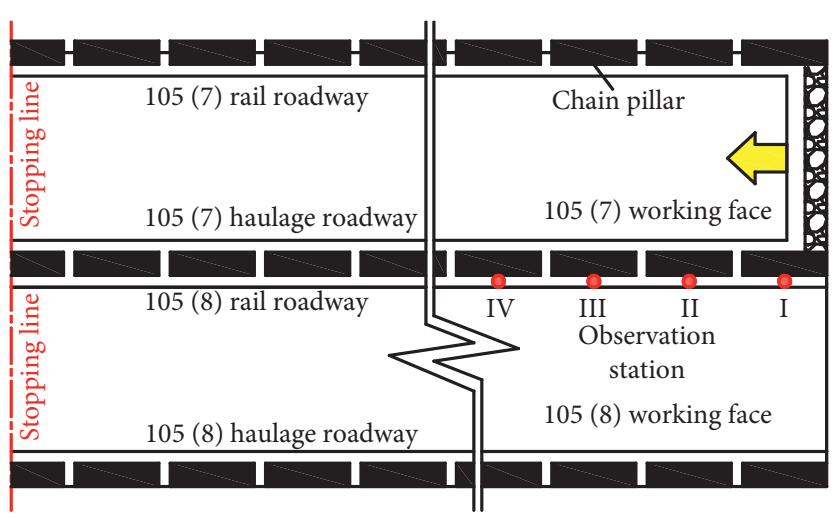

Figure 10: Observation station layout.

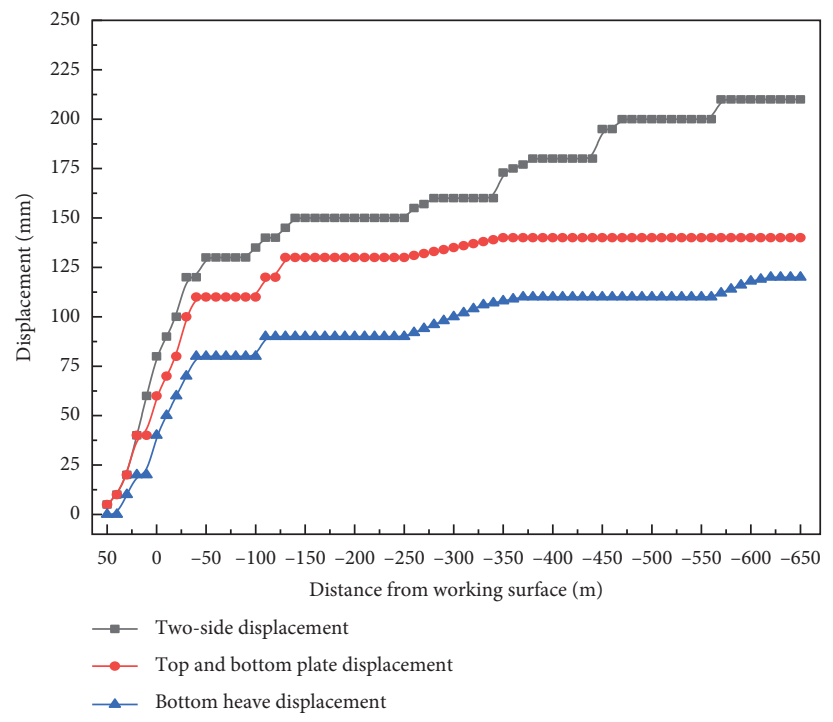

FIGURE 11: Observation of roadway displacement influenced by mining at upper section working face(105 (7) working face).

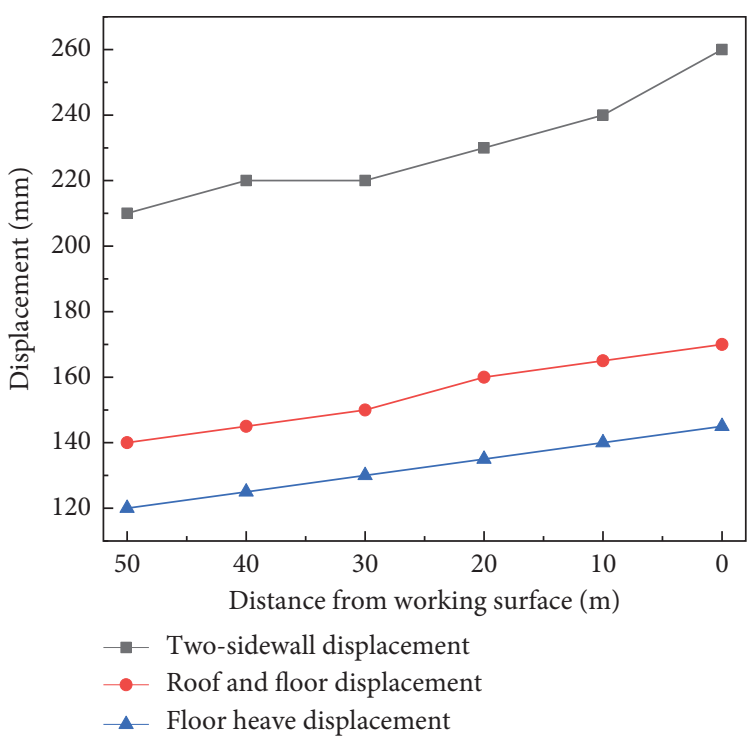

FIGURE 12: Observation of roadway displacement influenced by mining in this section working face(105 (8) working face). 


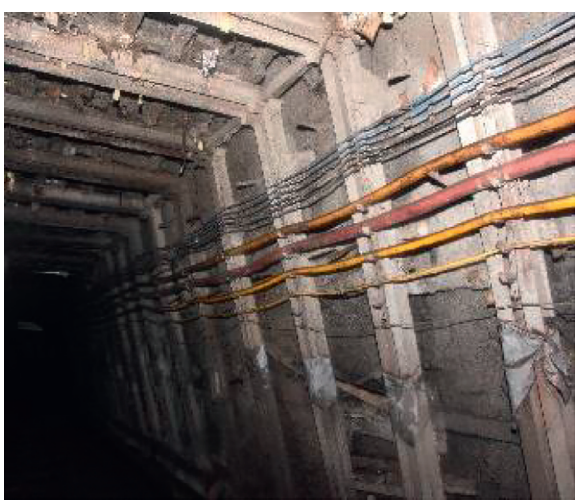

(a)

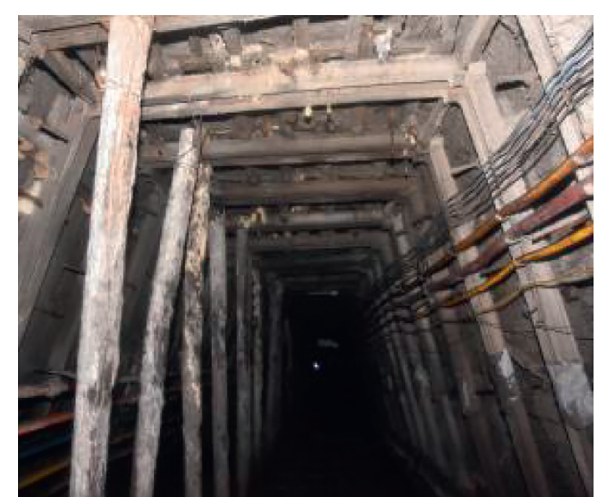

(b)

FiguRE 13: Optimization supporting effect of trapezoidal roadway. (a) Middle section. (b) Advanced support section.

\section{Conclusion}

This paper uses complex variable theory and elastic theory to study the tangential stress of surrounding rock of trapezoidal roadways and draws the following conclusions:

(1) The analytical solution is obtained by the complex change theory, the stress value obtained by calculation is only related to the ground stress, the lateral pressure coefficient, and the size of the roadway section, and it has nothing to do with the mechanical parameters of the surrounding rock of the roadway. Therefore, this value is not the actual stress value of the engineering roadway's surrounding rock. The analytical solution is consistent only in the regularities of stress distribution, which can reflect the stress state of a roadway with a certain shape section and can provide a theoretical basis for the selection of the shape and size of the roadway section and the support scheme.

(2) The tangential stress fitting curve of surrounding rock around the roadway shows that the top corner of the trapezoidal roadways is not affected by stress concentration, and the maximum stress concentration degree at the bottom corner is 2 . The overall stress distribution of the roof is uniform, while the stress distribution of the two sidewalls and the floor varies greatly, and the maximum stress difference is 12.3 $\mathrm{MPa}$. In addition, the stress concentration of the lower part of the sidewall and bottom corner is large, so reinforcement measures should be taken in the design of roadway support.

(3) The results of the study on the surrounding rock control of the trapezoidal roadways show that the design of the trapezoidal roadway support should take the two sidewalls and floor near the bottom corner as the main support focus. Based on the design of bolting with wire mesh and anchor cable $+\mathrm{W}$-type steel belt + joist steel shed support, this paper proposes three-time grouting reinforcement for the middle of the two sidewalls, the lower sidewall, and the floor. The field application results show that the support scheme can meet the highintensive mining requirements of the working face, and there is no need for repair during the service period.

\section{Data Availability}

The data used to support the findings of this study are available from the corresponding author upon request.

\section{Conflicts of Interest}

The authors declare that they have no conflicts of interest.

\section{Acknowledgments}

The study was supported by the National Natural Science Foundation of Surface Project of China (nos. 51774289 and 51404270) and the Open Fund of State Key Laboratory of Green and Safe Development of Western Coal (SKLCRKF1903).

\section{References}

[1] M. C. He, "Research Progress and challenge of deep soft rock engineering," Journal of China Coal Society, vol. 39, pp. 1409-1417, 2014.

[2] H. P. Kang, L. P. Si, and X. Zhang, "Research and application of underground stress distribution characteristics in shallow coal mine," Journal of China Coal Society, vol. 41, no. 6, pp. 1332-1340, 2016.

[3] Q. Meng, L. Han, Y. Chen et al., "Influence of dynamic pressure on deep underground soft rock roadway support and its application," International Journal of Mining Science and Technology, vol. 26, no. 5, pp. 903-912, 2016.

[4] G. E. Exadaktylos, P. A. Liolios, and M. C. Stavropoulou, "A semi-analytical elastic stress-displacement solution for notched circular openings in rocks," International Journal of Solids and Structures, vol. 40, no. 5, pp. 1165-1187, 2003.

[5] A. Z. Lv, X. L. Zhang, and S. J. Wang, "Analytic method for elasto-plastic analysis of eircular tunnels under non-axisymmetric streses," Chinese Journal of Rock Mechanics and Engineering, vol. 37, pp. 14-22, 2018. 
[6] L. Y. Yu, X. P. Chen, L. J. Han et al., "Elastic analysis of surrounding rock for underwater tunnels based on functions of complex variables method," Rock and Soil Mechanics, vol. 33, pp. 345-351, 2012.

[7] Z. L. Wang, L. F. Shen, J. Yao et al., "Calculation of stress field in surrounding rocks of shallow tunnel using computational function of complex variable method," Rock and Soil Mechanics, vol. 31, pp. 86-90, 2010.

[8] A. Lu, X. Zeng, and Z. Xu, "Solution for a circular cavity in an elastic half plane under gravity and arbitrary lateral stress," International Journal of Rock Mechanics and Mining Sciences, vol. 89, pp. 34-42, 2016.

[9] K.-H. Park, "Analytical solution for tunnelling-induced ground movement in clays," Tunnelling and Underground Space Technology, vol. 20, no. 3, pp. 249-261, 2005.

[10] J. W. Yang, Z. Tang, F. He et al., "Analysis of the complex functions of the sur-rounding rock stress field in the elastic circu-lar tunnels," Journal of Safety and Environment, vol. 15, pp. 148-152, 2015.

[11] Y. G. Wei, "Perturbation solution of elastoplastic analysis of circular tunnel under two-way unequal pressure," Geotechnical Engineering, vol. 12, pp. 11-20, 1990.

[12] G. Y. Hou, J. J. Li, W. W. Zhao et al., "Perturbation solutionsc for elasto-plastic problems of circular tunnel under unequal compression," Chinese Journal of Rock Mechanics and Engineering, vol. 33, pp. 3639-3647, 2014.

[13] L. W. Chen, J. B. Peng, W. Fan et al., "Analysis of surrounding rock mass plastic zone of round tunnel undernon-uniform stress field based on the unified strength theory," Journal of China Coal Society, vol. 30, pp. 20-23, 2007.

[14] Z. Q. Zhao, N. J. Ma, H. T. Lu et al., "The theory of butterfly failure of roadway and its application prospect," Journal of China University of Mining and technology, vol. 47, pp. 969978, 2018.

[15] N. J. Ma, X. D. Zhao, Z. Q. Zhao et al., "Stability analysis and control technology of mine roadway roof in deep mining," Journal of China Coal Society, vol. 40, pp. 2287-2295, 2015.

[16] X. F. Guo, N. J. Ma, X. D. Zhao et al., "General shapes and criterion for surrounding rock mass plastic zone of round roadway," Journal of China Coal Society, vol. 41, pp. 18711877, 2016.

[17] G. Zhao and S. Yang, "Analytical solutions for rock stress around square tunnels using complex variable theory," International Journal of Rock Mechanics and Mining Sciences, vol. 80, pp. 302-307, 2015.

[18] Z. Q. Wang, C. Wu, L. Shi et al., "Analysis of surrounding rock stress and plastic zone of two-way unequal pressure circular roadway based on complex variation theory," Journal of China Coal Society, vol. 44, pp. 419-429, 2019.

[19] Z. L. Xu, Elastic mechanics, Beijing: Higher Education Press, Beijing, China, 2016.

[20] Z. M. Chen, Analytical Method in Mechanical Analysis of Surrounding RockCoal press, Beijing, China, 1994.

[21] Department of Advanced Mathematics, Xi'an Jiaotong University, Complex Variables FunctionsHigher Education Press, Beijing, Beijing, China, 2003.

[22] A. Z. Lv and Q. W. Wang, "A new method for solving the mapping function of roadway with arbitrary section shape by using optimal technology," Chinese Journal of Rock Mechanics and Engineering, vol. 14, pp. 269-274, 1995. 